\title{
ESPAÑOL A LA CATALANA: VARIACIÓN VERNÁCULA E IDENTIDAD EN LA CATALUÑA SOBERANISTA*
}

\author{
José Luis Blas Arroyo \\ Universitat Jaume I
}

\section{RESUMEN}

Los resultados del presente estudio muestran una notable correlación entre las realizaciones vernáculas de un segmento fónico del español y la filiación ideológica de los políticos catalanes. A partir de una muestra integrada por 16 destacados miembros de la política catalana actual, que adquirieron un notable protagonismo en el proceso soberanista vivido en Cataluña en los últimos años, un análisis variacionista demuestra que las formas velarizadas del fonema (1) en posición final de palabra ('fatal' [fatáł]) -al modo en que este fonema es pronunciado en catalán- están íntimamente asociadas al ideario nacionalista -y más concretamente independentista de los políticos-, y en menor medida a su origen social. Por el contrario, aparte de un par de restricciones estructurales vinculadas al contexto fónico, ningún otro factor lingüístico o extralingüístico muestra una incidencia relevante, incluida la ideología, entendida en el eje tradicional derecha-izquierda. En el marco de la denominada tercera ola de los estudios variacionistas (Eckert 2012), estos datos avalan la interpretación de esta variable fónica como un potencial recurso para la expresión de determinadas filiaciones políticas e ideológicas en circunstancias excepcionales como las vividas recientemente en Cataluña.

PALABRAS CLAVE: variación fónica, velarización de (l), identidad lingüistica, nacionalismo, ideología, lenguas en contacto, catalán, español.

\section{ABSTRACT}

The results of the present study show a remarkable correlation between a vernacular phonological variant and the ideological affiliation of current Catalan politicians. From a sample composed of 16 leading Catalan politicians, a variationist analysis shows that the velarized forms of the phoneme (1) in final position ('fatal' [fatáł]) -the way this segment is pronounced in Catalan- are intimately

* El presente artículo se integra dentro del proyecto de investigación «Dimensiones estructurales, sociales e idiolectales del cambio lingüístico: nuevas aportaciones desde la sociolingüística al estudio del español» financiado por el Ministerio de Economía y Competitividad (2018-2021) (Ref. FFI2017-86194-P). 
associated with the nationalist ideology -more specifically, independentist- and, to a lesser extent, with the politicians social background. On the contrary, apart from a couple of structural constraints linked to the phonic context, no other linguistic or extralinguistic factor shows a relevant incidence, including ideology, understood this time in the traditional right-left axis. Within the framework of the so-called third wave of variation studies (Eckert 2012), these data support the interpretation of this phonological variable as a potential resource for the expression of political and ideological identity in exceptional circumstances such as those experienced recently in Catalonia.

KEYWORDS: Phonological variation, velarization of (l), linguistic identity, nationalism, ideology, languages in contact, Catalan, Spanish.

Fecha de recepción: 20/04/2018

Fecha de aceptación: 14/07/2018

Fecha de la versión definitiva: 20/07/2018

\section{INTRODUCCIÓN}

El español oral en las comunidades del habla del ámbito lingüístico catalán contiene algunas singularidades cuya explicación puede hallarse en no pocos casos en la influencia ejercida por el contacto secular con el catalán (Badia 1981; Sinner 2004; Sinner y Wesch 2008; Blas Arroyo 2004, 2011). Los ejemplos siguientes, extraídos de un corpus de habla oral compilado para la ocasión, y que tiene como protagonistas a políticos destacados de la actual coyuntura política catalana, son ilustrativos de algunas de esas particularidades:

(1) ... el catalán que es una lengua que no es lengua reconocida $\boldsymbol{a}$ la Unión Europea porque el Estado español no quiere (Carme Forcadell, 27/08/ 2014).

(2) ... y creemos que también ha estado esto decisivo para poder ... convocar un acto de:: de rebuig de repulsa, un acto de repulsa... (Joaquim Forn, $31 / 08 / 2017)$.

(3) ... me llamaron los responsables del hotel diciendo que estaban absolutamente impactados por lo que había... habían visto al largo de todo de todo el día... (Monserrat Candini, 03/10/2017).

(4) ... cuando yo me presenté dije: no pot ser, no puede ser, el Partido Popular se tiene que presentar... (Dolors Monserrat, 17/10/2017).

(5) Yo creo que queda claro que no se no se puede tulerar que nadie puede amenazar a alguien sencillamente por defender la democracia (Marta Pascal, 03/10/2017).

Los fragmentos de (1) a (3) muestran calcos de estructuras gramaticales del catalán, ajenas a la norma del español, como sucede con algunas prepo- 
siciones (1) (esp. «reconocida en la Unión Europea»), ciertos usos de estar por ser (2) (esp. "ha sido esto decisivo») o traducciones literales de locuciones adverbiales como las de (3) (cat. «al llarg»; esp. «a lo largo»). Al mismo tiempo, los fragmentos de (2) y (4) contienen sendas muestras de cambio de código, con dos de las funciones más habituales de esta modalidad del discurso bilingüe: el paso de una lengua otra ante una laguna léxica (2) y la reproducción de una cita textual (4). Por último, el ejemplo (5) ilustra uno de los fenómenos frecuentes de interferencia fónica, el cierre de la /o/ en posición átona.

Rasgos como los reseñados se han descrito como relativamente habituales en el habla espontánea de muchos catalanes, aunque con diferencias frecuenciales destacadas en función de razones lingüísticas (puntos de coincidencia o conflicto estructural, grado de ocurrencia en el discurso...) o extralingüísticas (diferencias sociolectales, generacionales, idiolectales, etc.). Con todo, en los últimos tiempos estos rasgos vernáculos han adquirido un mayor protagonismo por su presencia habitual en los medios de comunicación, especialmente en boca de personajes públicos, como periodistas, deportistas, políticos, etc. Ello ha conducido a un debate creciente acerca del grado de dominio del español en la Cataluña actual, lo que se ha puesto en relación con algunas prácticas de la política lingüística que, desde hace varias décadas, obligan a la inmersión lingüística en catalán en todo el sistema educativo, con independencia de la lengua dominante del alumnado.

Para algunos, muestras como las de (1) a (5), más aún en boca de políticos de los que se espera un nivel cultural elevado y unos usos expresivos en consonancia, serían la manifestación más palpable del deterioro al que la lengua española se está viendo abocada en tierras catalanas en los últimos tiempos. Ahora bien, con independencia de que esto último sea o no una realidad, lo que no vamos a dilucidar aquí, lo cierto es que la anterior no es la única manera posible de interpretar las cosas. En la práctica, ¿y si quienes se expresan de esta manera muestran en el fondo una cierta autoindulgencia con el uso de una lengua que no es la suya, y que en no pocos casos se ven obligados a utilizar debido al cargo público que ocupan en una sociedad oficialmente bilingüe? O, más aún, ¿podrían interpretarse estos rasgos vernáculos como potenciales actos de identidad (Le Page y Tabouret Keller 1985) o, cuando menos, como actos indiciarios (indexical acts) (Eckert 2008) en un momento histórico como el presente, en el que se debate nada menos que las relaciones futuras de Cataluña con España, y no -o al menos no solo- como un mero reflejo del origen social y dialectal de sus hablantes?

Para intentar dar alguna respuesta a estos interrogantes, y en línea con algunas investigaciones recientes que han visto en la variación fónica un fértil ámbito de estudio para el análisis de las relaciones con la identidad 
política (Krivoruchko 2009; Hall-Lew, Coppock y Starr 2010; Silva et al. 2011; Hall-Lew, Stark y Coppock 2012; Podesva et al. 2015; Hall-Lew y Friskney 2017, entre otros), en lo que sigue ofrecemos los resultados de un estudio variacionista acerca de una de las variables fónicas más singularmente asociadas a la pronunciación vernácula del español en Cataluña: la consonante $/ 1 /$ en posición final de palabra. Junto a la pronunciación alveolar, característica del español estándar (Quilis et al. 1979; Hidalgo y Quilis 2012; Martínez Celdrán y Fernández Planas 2013; Hualde 2014), este segmento muestra en tierras catalanas una realización alternativa, de carácter velar, que sigue de cerca los hábitos articulatorios de la lengua autóctona (Badia 1983; Carreras et al. 1992; Prieto 2011; Fernández Planas 2011; IEC 2016). Para ello, analizaremos un corpus oral elaborado a partir del habla de 16 políticos, todos ellos con un conocimiento nativo del catalán. Esta muestra se ha confeccionado cuidadosamente al efecto de que en ella se encuentren representados de manera equilibrada diversos factores que podrían asociarse con la identidad lingüística, tales como el sexo, el origen social, la procedencia geográfica y la filiación ideológica, tanto en el eje tradicional izquierda/derecha como en el debate acerca de la cuestión nacional (nacionalistas/no nacionalistas).

Antes de proceder al análisis de los resultados, en $\S 1$ ofrecemos un breve resumen de la situación reciente en Cataluña, como telón de fondo histórico al debate planteado. Por su parte, el apartado 2 da cuenta de los principales detalles del corpus, al tiempo que en los dos siguientes se muestra la delimitación de la variable lingüística (\$3) y el proceso de codificación e hipótesis de partida $(\$ 4)$. En $\$ 5$ se exponen las cuestiones metodológicas más destacadas, con especial atención al análisis cuantitativo, que conjuga una estadística descriptiva inicial, con modelos de regresión más sofisticados, con los que es posible obtener un diagnóstico más ajustado acerca de las fuerzas estructurales y no estructurales que explican la variación. Por último, el análisis detallado de los datos en $\$ 6$ dará paso a una síntesis de las principales conclusiones derivadas del estudio $(\$ 7)$.

\section{El CONTEXTO: TENSIÓN POlítica y SOCIAL EN unA CATAluña DivididA}

Los hechos que se resumen en este apartado son bien conocidos por quienes han seguido de cerca la actualidad catalana en los últimos años. Desde la sentencia del estatuto de Cataluña por parte del Tribunal Constitucional (2010), en la que se enmendaban algunos artículos de la norma aprobada en referéndum en 2006, pero, sobre todo, desde la ruptura de las negociaciones para dotar a Cataluña de un estatus fiscal más favorable, a partir de 2012 los sectores catalanes más nacionalistas se lanzaron en pos 
de un proceso (el omnipresente procés) favorable a la independencia de esta comunidad autónoma del Estado español. Este largo e inacabado proceso ha contado con diversos hitos, como manifestaciones multitudinarias en las convocatorias anuales de la Diada, de proporciones nunca vistas anteriormente, o la convocatoria de dos referéndums en los últimos años. El primero, considerado no vinculante por las propias autoridades nacionalistas, en noviembre de 2014, dio paso a unas elecciones plebiscitarias donde una gran coalición nacionalista, Junts pel Sí, planteó la legislatura con dos objetivos fundamentales: convocar un nuevo referéndum, esta vez sí vinculante, y (si el resultado de este era favorable a las tesis secesionistas), decretar la independencia mediante una declaración unilateral, dando origen así a la nueva república de Cataluña.

Tras un periodo previo de considerables algaradas, con las leyes de desconexión y referéndum aprobadas por las fuerzas nacionalistas en el parlamente catalán y el rechazo unánime de las no nacionalistas, este segundo referéndum se celebró finalmente el día 1 de octubre de 2017. En él se produjeron numerosos enfrentamientos entre los ciudadanos que querían votar y las fuerzas de orden público enviadas por el gobierno español con el fin de impedirlo, con imágenes que dieron la vuelta al mundo. Tras la victoria del sí en el referéndum por una amplia mayoría ${ }^{1}$, el presidente de la Generalitat, Carles Puigdemont, realizó una extraña Declaración unilateral de independencia, por la que proclamaba el nacimiento de la nueva república independiente de Cataluña, y que, sin embargo, pocos segundos después dejaba en suspenso con el pretendido objetivo de negociar con el estado español los términos de la desconexión. Tales negociaciones no solo no se produjeron, sino que dieron paso a la intervención de la comunidad autónoma por parte del gobierno español mediante la aplicación de artículo 155 de la Constitución, que prevé la suspensión de la autonomía en caso de vulneración del orden constitucional. Junto a esta suspensión, las autoridades judiciales procesaron, y en algunos casos encarcelaron, a los principales responsables políticos, lo que propició la huida del presidente de la Generalitat y de cinco de sus exconsejeros a Bruselas. La crisis se saldó, tan solo momentáneamente, con la convocatoria de elecciones autonómicas el 20 de diciembre de 2017, que volvieron a ganar los sectores nacionalistas, no sin una fuerte subida del principal partido de la oposición, Ciudadanos, que, con el $36 \%$ de los votos, fue la fuerza política más votada.

La muestra analizada en el presente estudio se extiende a lo largo de toda una década, desde 2007 -poco después de la aprobación del actual

\footnotetext{
${ }^{1}$ Mayoría en términos relativos, ya que en el referéndum votó menos de la mitad del censo electoral, incluida la inmensa mayoría de quienes se mostraron contrarios a la consulta por considerarla ilegal.
} 
Estatuto de Cataluña- hasta esa campaña electoral de diciembre de 2017. Con todo, en ella adquiere un especial protagonismo el discurso político desarrollado durante ese último año, el de mayor efervescencia del procés y, en particular, el que tuvo lugar en torno a la convocatoria del referéndum por la independencia durante los meses de septiembre y octubre de 2017.

\section{El CORPuS}

La tabla 1 (página siguiente) resume algunos datos biográficos de los políticos que integran esa muestra. Junto al nombre y el partido político o la institución representados en las dos primeras columnas, en las siguientes se da cuenta, respectivamente, de los siguientes datos: sexo, año del discurso, lugar de procedencia, origen social, ideología política y orientación en el eje del catalanismo político.

La selección se ha hecho de acuerdo con diversos criterios. En primer lugar, se trata en todos los casos de personajes públicos que tienen el catalán como lengua materna -en solitario o en combinación con el español, en los casos de descendientes de matrimonios mixtos-, y que adquirieron un protagonismo destacado en el debate político en torno a la independencia de Cataluña, especialmente en la parte final del procés. En segundo lugar, en la muestra están representados de la forma más equilibrada posible algunos de los principales factores extralingüísticos que nos interesan. Así, cuenta con un número idéntico de políticos nacionalistas y no nacionalistas (ocho en cada grupo) y algo similar ocurre con la ideología política (ocho representantes de centro-derecha y otros tantos de la izquierda) y el origen social (ocho nacieron en familias humildes, frente a otros en sectores sociales más acomodados). La distribución por sexos no es tan equilibrada, pero está cerca de conseguirlo: 9 hombres y 7 mujeres. Y lo mismo ocurre con el origen geográfico de los políticos: mientras que 7 proceden de la ciudad de Barcelona, los 9 restantes lo hacen de otras comarcas de Cataluña.

La proyección mediática de los miembros de la muestra es diferente. Así, hay políticos muy conocidos por todo el público -no solo catalán-, y su presencia en los medios de comunicación ha sido una constante en los últimos años, como sucede con el expresidente del Partido Popular en Cataluña, Xavier Albiol, la alcaldesa de Barcelona, Ada Colau, la exministra socialista, Carme Chacón (fallecida en abril de 2017), el líder del partido Ciudadanos, Albert Rivera, o Joan Tardà, diputado por Esquerra Republicana de Catalunya en el parlamento español desde el año 2011. Junto a estos, figuran otros, menos conocidos por el público general, pero que adquirieron un notable liderazgo en las semanas previas y posteriores a la 
TABLA 1. Distribución de los individuos de la muestra por factores extralingüisticos

\begin{tabular}{|c|c|c|c|c|c|c|c|}
\hline NOMBre & Partido & SEXo & $\begin{array}{l}\text { AÑO } \\
\text { NAC. }\end{array}$ & LUGAR & $\begin{array}{l}\text { ORIGEN } \\
\text { SOCIAL }\end{array}$ & IDEOLOGÍA & NACIONALISTA \\
\hline $\begin{array}{l}\text { Albiol, } \\
\text { Xavier }\end{array}$ & $\begin{array}{l}\text { Partido } \\
\text { Popular }\end{array}$ & $\mathrm{H}$ & 1967 & Badalona & Humilde & Dcha & No \\
\hline $\begin{array}{l}\text { Candini, } \\
\text { Montserrat }\end{array}$ & $\begin{array}{l}\text { CIU, } \\
\text { PdCat }\end{array}$ & M & 1957 & Barcelona & Otros & Dcha & Sí \\
\hline $\begin{array}{l}\text { Chacón, } \\
\text { Carme }\end{array}$ & PSC & M & 1971 & Esplugues & Otros & Izda & No \\
\hline Colau, Ada & $\begin{array}{l}\text { Barcelona } \\
\text { en comú }\end{array}$ & M & 1974 & Barcelona & Humilde & Izda & No \\
\hline $\begin{array}{l}\text { Coscubiela, } \\
\text { Joan }\end{array}$ & $\begin{array}{c}\text { Iniciativa } \\
\text { per Cataluny }\end{array}$ & $\mathrm{H}$ & 1954 & Barcelona & Humilde & Izda & No \\
\hline $\begin{array}{c}\text { Duran i Lleida, } \\
\text { Josep }\end{array}$ & CIU & $\mathrm{H}$ & 1952 & Alcampell & Otros & Dcha & Sí \\
\hline $\begin{array}{l}\text { Forcadell, } \\
\text { Carme }\end{array}$ & $\begin{array}{c}\text { ANC, } \\
\text { Esq. Republ. }\end{array}$ & M & 1955 & Cherta & Humilde & Izda & Sí \\
\hline $\begin{array}{l}\text { Girauta, } \\
\text { Juan Carlos }\end{array}$ & Ciudadanos & $\mathrm{H}$ & 1961 & Barcelona & Otros & Dcha & No \\
\hline Herrera, Joan & $\begin{array}{l}\text { Iniciativa } \\
\text { per Catal. }\end{array}$ & $\mathrm{H}$ & 1971 & Barcelona & Medio & Izda & No \\
\hline $\begin{array}{l}\text { Montserrat, } \\
\text { Dolors }\end{array}$ & $\begin{array}{l}\text { Partido } \\
\text { Popular }\end{array}$ & M & 1973 & $\begin{array}{c}\text { San } \\
\text { Sadurní }\end{array}$ & Otros & Dcha & No \\
\hline Pascal, Marta & CIU, PdCat & $\mathrm{M}$ & 1983 & Vic & Otros & Dcha & Sí \\
\hline Rivera, Albert & Ciudadanos & $\mathrm{H}$ & 1979 & Barcelona & Otros & Dcha & No \\
\hline Rovira, Marta & $\begin{array}{c}\text { Esquerra } \\
\text { Republ. }\end{array}$ & M & 1977 & Vic & Humilde & Izda & Sí \\
\hline $\begin{array}{l}\text { Sànchez, } \\
\text { Jordi }\end{array}$ & $\begin{array}{c}\text { ANC, Junts } \\
\text { per Catal. }\end{array}$ & $\mathrm{H}$ & 1964 & Barcelona & Humilde & Izda & Sí \\
\hline Tardà, Joan & $\begin{array}{l}\text { Esquerra } \\
\text { Republic. }\end{array}$ & $\mathrm{H}$ & 1953 & Cornellà & Humilde & Izda & Sí \\
\hline Turull, Jordi & CIU, PdCat & $\mathrm{H}$ & 1965 & Parets & Humilde & Dcha & Sí \\
\hline
\end{tabular}

celebración del referéndum del 1 de octubre, como algunos diputados en el Parlamento catalán (Monserrat Candini, Joan Coscubiela, Jordi Turull, Carme Forcadell, Marta Rovira), la ministra de sanidad Dolors Montserrat, el diputado en el parlamento nacional por Ciudadanos, Juan Carlos Girauta, o el presidente de la Asamblea Nacional Catalana, Jordi Sànchez. Final- 
mente, contamos también con una pequeña representación de personajes públicos que desempeñaron un importante papel en las primeras fases del procés, pero que en 2017 se habían retirado ya de la primera línea política por razones diversas. Es el caso de Josep A. Duran i Lleida, veterano representante del nacionalismo catalán en el Parlamento español, o del exdiputado en el Parlamento de Cataluña, Joan Herrera, líder en su momento de la coalición Iniciativa per Catalunya.

\section{LA VARIABLE LINGÜÍSTICA}

La consonante / $/$ es un fonema consonántico que se incluye dentro del paradigma de los fonemas laterales junto a $/ \chi /$. Desde una perspectiva acústica, estas consonantes se caracterizan por la presencia de rasgos similares a los vocálicos, aunque su intensidad sea menor (Quilis et al. 1979; Fernández Planas 2011; Martínez Celdrán y Fernández Planas 2013; Hualde 2014).

En español, la realización estándar de /1/ es alveolar, si bien en determinados contextos silábicos se asimila al punto de articulación de otros fonemas, con la excepción de los labiales y velares, un hecho este último que distingue esta lengua de otras como el inglés o el catalán. Esta asimilación permite la distinción de diversos alófonos linguoalveolares, que, siguiendo a Hidalgo y Quilis (2012: 205), podemos resumir en los siguientes:

a) alveolar propiamente dicho, en posición silábica prenuclear precediendo a una vocal (ala) y en posición silábica postnuclear seguido de vocal, pausa o cualquier consonante que no sea $[\mathrm{t}],[\mathrm{d}],[\theta][\mathrm{t}]$ (cala);

b) linguointerdental, cuando precede a una [0] (calzar);

c) linguodental, en presencia de [t] y [d] (el toldo); y

d) linguopalatalizada, en posición silábica postnuclear y precediendo a una consonante palatal (el chico).

Lo anterior vale para la mayoría de los dialectos del español, si bien hay una notable excepción en las variedades en contacto con la lengua catalana, donde es frecuente la interferencia de una [ł] velarizada, cuya frecuencia, en opinión de Hualde (2014: 178) depende «[de] la preferencia del hablante». De hecho, en la fonética del catalán, la /1/ se considera también una consonante lateral alveolar, aunque en las variedades nordoccidental y oriental -nuestro caso- su realización es más oscura y velarizada, o, lo que es lo mismo, "presenta com a articulació secundària una aproximació del dors de la llengua a la zona velar o faríngia» (IEC 2016: 64). Ello es especialmente así en determinados contextos, como entre vocales no palatales ( mula), en la segunda posición de una combinación consonántica (pla), de- 
lante de consonantes labiales y velares (alba, colgar) y en posición de coda silábica (sol) (Fernández Planas 2011: 161; IEC 2016: 64).

En el presente estudio nos centramos en la potencial influencia de la lengua catalana en el último contexto mencionado y, en particular, en la posición final de palabra. Con todo, en la muestra se han excluido las ocurrencias del artículo $e l$, así como de las contracciones al y $d e l$, ya que la enorme frecuencia en el discurso de estas palabras podría afectar a la representatividad de los datos.

Por lo que a las variantes se refiere, para el análisis de regresión binario tan solo se consideran dos. Por un lado, agrupamos en un único bando todas las realizaciones alveolares, al margen de los matices articulatorios específicos mencionados más arriba. Frente a estas, consideramos todas las pronunciaciones velares, con independencia del grado de velarización, así como de la intensidad y duración del sonido, que en ocasiones pueden diferir considerablemente entre unos hablantes y otros, y aun en el discurso de un mismo informante. Estas últimas nos servirán como variante de referencia en el análisis empírico.

\section{CODIFICACIÓN E HIPÓTESIS}

En la tabla 2 (página siguiente) se sintetizan los parámetros utilizados en la codificación de la variable lingüística y que nos sirven para poner a prueba una serie de hipótesis acerca del modo en que el contexto variable puede afectar al segmento (l) en posición final de palabra.

De estos parámetros, seis son de carácter lingüístico. El primero pretende comprobar si el grado de la pronunciación velar está significativamente relacionado con el timbre de la vocal previa, siendo tres los contextos posibles:

a) vocal central (a),

b) vocales palatales $(\mathrm{e}, \mathrm{i}), \mathrm{y}$

c) vocales velares $(\mathrm{o}, \mathrm{u})$.

La hipótesis de partida es que el grado de velarización seguirá de cerca los patrones característicos de la lengua catalana, de manera que aquel será mayor en presencia de las vocales central y velares, y menor antes las palatales:

(6) ... y una ley como está que el sector audiovisual lo estaba esperando mucho (Jordi Turull)

(7) Combatir la pobreza infantil es imposible con ese empleo precario al que hace referencia (J. A. Duran i Lleida)

(8) ... tengo familia y amigos al conjunto del Estado del Estado español y grandes amigos (M. Candini) 
TABLA 2. Resumen de los factores considerados en el análisis

\begin{tabular}{|c|c|c|}
\hline $\begin{array}{c}\text { NOMBRE } \\
\text { DE LA VARIABLE }\end{array}$ & BREVE DESCRIPCIÓN & FACTORES \\
\hline VOCAL PREVIA & Vocal previa a la (l) final & $\begin{array}{l}\text { Central (a), Palatales } \\
(\mathrm{e}, \mathrm{i}), \text { Velares }(\mathrm{o}, \mathrm{u})\end{array}$ \\
\hline $\begin{array}{l}\text { COTEXTO } \\
\text { SIGUIENTE }\end{array}$ & Contexto fónico siguiente a la (l) final & $\begin{array}{l}\text { Pausa, Consonante, } \\
\text { Vocal }\end{array}$ \\
\hline $\begin{array}{l}\text { LONGITUD } \\
\text { DE PALABRA }\end{array}$ & $\begin{array}{l}\text { Longitud de la palabra medida en número } \\
\text { de sílabas }\end{array}$ & Variable continua \\
\hline CLASE DE PALABRA & Paradigma al que pertenece la palabra & $\begin{array}{l}\text { Adjetivo, Sustantivo, } \\
\text { Otras }\end{array}$ \\
\hline FRECUENCIA 1 & N. ${ }^{\circ}$ de ocurrencias de la palabra en el corpus & Variable continua \\
\hline FRECUENCIA 2 & Frecuencia de la palabra en el español actual & Variable continua \\
\hline TIPO DE DISCURSO & $\begin{array}{l}\text { Carácter preferentemente dialogal } \\
\text { (entrevistas, ruedas de prensa, tertulias...) } \\
\text { o monologal (parlamentos, conferencias, } \\
\text { mítines...) del discurso }\end{array}$ & Dialogales/Monologales \\
\hline CATALANISMO & $\begin{array}{l}\text { Orientación política en el eje } \\
\text { nacionalismo/no nacionalismo }\end{array}$ & $\begin{array}{l}\text { Nacionalistas, } \\
\text { No nacionalistas }\end{array}$ \\
\hline IDEOLOGÍA & $\begin{array}{l}\text { Orientación política en el eje derecha/ } \\
\text { izquierda }\end{array}$ & Derecha, Izquierda \\
\hline ORIGEN SOCIAL & Extracción social familiar del político & Humilde, Otros \\
\hline Procedencia & Lugar de nacimiento & Barcelona, Resto \\
\hline SEXo & Sexo & Mujer, Hombre \\
\hline EDAD & Año de nacimiento & Variable continua \\
\hline AÑo & Año en que tuvo lugar el discurso & Variable continua \\
\hline NOMBRE & Nombre del político & $\begin{array}{l}\text { Variable aleatoria } \\
\text { (16 valores) }\end{array}$ \\
\hline PALABRA & Palabra afectada & $\begin{array}{l}\text { Variable aleatoria } \\
\text { (162 valores) }\end{array}$ \\
\hline
\end{tabular}

Un segundo factor estructural es el representado por el entorno fónico siguiente, en el que distinguimos inicialmente otras tres posibilidades:

a) consonante siguiente, como en (9),

b) vocal siguiente, como en (10); y

c) pausa, como en (11). 
De los tres, esperamos una incidencia más significativa de las velarizaciones en los contextos prepausales, por ser estos los menos afectados por una potencial asimilación a los sonidos siguientes, seguidos por los preconsonánticos, en consonancia con las normas reseñadas del catalán. Por el contrario, es de prever un menor número de variantes vernáculas en los contextos prevocálicos:

(9) ... la vía unilateral no existe o sea esto es un invento patentado por parte del Estado español (M. Rovira)

(10) ... era el aniversario ¿no? de: de: después de este fatal atentado de Hipercor (M. Pascal)

(11) ... yo estoy convencido que la capacidad de resistencia pacífica... se mantenga hasta el final $\_$creo que nadie puede dudar de nuestra actitud pacífica (J. Sànchez)

El tercer factor atiende a la longitud de la palabra, medida a través del número de sílabas, y por tanto, concebido como una variable continua en el análisis de regresión. Por otro lado, desde un punto de vista categorial, las palabras terminadas en (1) se distribuyen en tres grandes paradigmas. La mayor representación se la llevan los adjetivos (constitucional, español, social, legal, etc.), categoría a la que pertenece el $71 \%$ de todos los términos del corpus. A mucha distancia, le siguen los sustantivos (abril, concejal, hospital, fútbol, etc.) (16\%) y una categoría ómnibus (Otras, en la codificación), en la que agrupamos las ocurrencias de diversos paradigmas, como pronombres (cual, cuál), adverbios ( $m a l)$ y determinantes (aquel, tal) (13\%). La hipótesis es que, dado que el segmento (1) aparece de forma mucho más recurrente en los adjetivos, será esta la categoría donde, proporcionalmente, habrá más velarizaciones.

El criterio frecuencial preside también los dos siguientes predictores, con los que se cierra el apartado lingüístico. No obstante, esta frecuencia se medirá de acuerdo con dos criterios, cuya potencial influencia analizamos por separado:

- Frecuencia 1: Número de ocurrencias de cada palabra en el corpus de discurso político.

- Frecuencia2: En este caso, se mide la frecuencia de la palabra en un corpus de español mucho más amplio, como el que proporciona la Real Academia a partir de los datos del Corpus de Referencia del Español Actual (CREA) ${ }^{2}$.

\footnotetext{
${ }^{2}$ Disponible en $<$ http://corpus.rae.es/lfrecuencias.html> (última consulta: 2/2/2018).
} 
La diferencia entre ambos criterios hace que, en el primer caso, pueden salir beneficiadas palabras con poca incidencia en el español general, pero con una elevada recurrencia en el discurso político (tribunal, constitucional, civil, etc.). Sea como sea, la hipótesis es también que, por razones de persistencia cognitiva (cognitive entrenchment) (Bybee 2006), conforme aumente la frecuencia de la palabra, aumentará en paralelo el número de velarizaciones; y viceversa, a menor frecuencia de los elementos léxicos, menor también el uso de las variantes vernáculas.

Por lo que al plano extralingüístico se refiere, en el estudio atendemos a otros seis factores:

- Sexo: En una situación de variación estable, una variante vernácula como la velarización de (l) sería más esperable en el habla masculina que en la femenina, dada la contrastada mayor inclinación de las mujeres a reproducir las normas de prestigio que los hombres en estas circunstancias (Labov 2001; Queen 2013). No obstante, cabe pensar también en la posibilidad de que se esté produciendo un cambio favorable a la variante, en cuyo caso las mujeres podrían abanderarlo (Labov 2001).

- Año: La posibilidad de que estemos asistiendo a un cambio en marcha, favorable a las velarizaciones, se pretende comprobar también con el concurso de este factor continuo, que, como se recordará, abarca un periodo de diez años, entre 2007 y 2017, aunque, como señalamos, cronológicamente distribuido de manera desigual.

- Igual carácter tiene el factor generacional (edad), medido a partir del año de nacimiento de los políticos. De haber un cambio favorable a las realizaciones vernáculas, este sería promovido preferentemente por las generaciones más jóvenes, que en la muestra actual están representadas por aquellos cuya edad oscila entre los 30 y 40 años. El resto, a partir de 55 años en adelante, mostraría un índice de velarizaciones menor. Claro que ese cambio podría ir en la dirección contraria, esto es, en retroceso, con lo que hallaríamos una mayor presencia de las articulaciones vernáculas entre los políticos de más edad.

- En el factor origen social no codificamos el estatus sociocultural alcanzado por los hablantes en el momento del habla, ya que la inmensa mayoría posee formación universitaria ${ }^{3}$, con estudios mayoritarios en el mundo del derecho y la economía. Sin embargo, nos interesa el origen familiar y, por tanto, la posibilidad de que las realizacio-

3 Tan solo dos de los dieciséis políticos no terminaron sus estudios universitarios (Albiol y Colau). 
nes vernáculas sean una huella de este. En ese sentido, esperamos que los políticos que proceden de entornos familiares más humildes se sitúen en cabeza de las velarizaciones, frente a los individuos vinculados a orígenes más acomodados ${ }^{4}$.

En el plano ideológico, los miembros de la muestra se dividen en dos grupos, que representan otras tantas opciones políticas. En el que codificamos bajo el rótulo de Derecha incluimos a políticos vinculados a partidos tradicionalmente considerados como de derechas (PP, CIU) o de centro-derecha (Ciudadanos). Por su parte, los integrantes del grupo Izquierda van desde las opciones socialdemócratas (Partit dels Socialistes de Catalunya, Esquerra Republicana) hasta las más avanzadas en este eje (Barcelona en Comú, Iniciativa Per Cataluña-Els Verds). La hipótesis de partida es que los partidos y coaliciones de izquierda serán más promotoras de las velarizaciones que los de derechas, por estar inicialmente más asociados a la cultura popular y, por tanto, más dotadas de un potencial prestigio encubierto (Trudgill 2000).

Con todo, en Cataluña, esta adscripción ideológica se cruza con otra no menos importante, de orientación nacional, que en no pocas ocasiones llega a neutralizar a la primera y por la que los políticos y sus grupos se definen como Nacionalistas o No nacionalistas. En el debate político catalán reciente, el nacionalismo está íntimamente ligado a las ansias independentistas, si bien hay excepciones, como la representada en la muestra por Josep Antoni Duran i Lleida, quien, tras muchos años como representante destacado de Convergencia i Unió en el parlamento español, renunció a su carrera política, desmarcándose de la estrategia independentista abanderada por sus otrora socios de coalición. Por otro lado, no todos los políticos definidos como no nacionalistas son insensibles a algunas de las reclamaciones históricas del catalanismo, como el derecho a decidir, aunque eso sí, alejado de cualquier unilateralismo y mediante una consulta legal pactada con el gobierno del Estado (Colau, Coscubiela, Herrera). Con todo, incluso en estos casos, sus representantes han señalado que, ante un hipotético referéndum, su voto sería contrario a la independencia.

- En el plano estilístico, el factor tipo de discurso permite comprobar si hay diferencias en el grado de velarización ante el carácter pre-

${ }^{4}$ A partir de los datos biográficos recabados, incluimos en el primer grupo a aquellos políticos que proceden de familias de extracción social baja o media-baja. Por el contrario, los agrupados en el segundo bloque comprenden a quienes descienden de entornos sociales más acomodados, ya sean clases medias o medias-altas. 
ferentemente dialogal o monologal del acto comunicativo en que interviene el político. El primero es el caso de entrevistas, ruedas de prensa, tertulias y debates; el segundo, el de intervenciones en el Parlamento, declaraciones institucionales, mítines, etc. Desde una perspectiva clásica del estilo (Labov 1972), cabría suponer que el mayor grado de atención que el hablante presta hacia su propia habla en estas últimas redundará en perjuicio de las realizaciones velares, al contrario que en las dialogales, donde el político no puede ejercer tanto control sobre su discurso y donde, por consiguiente, son previsibles mayores dosis de espontaneidad. Sin embargo, cabe pensar también en otros desenlaces estilísticos como los que establece la teoría de la acomodación (Giles, Coupland y Coupland 1991). De acuerdo con sus postulados, serían esperables mayores dosis de convergencia (o divergencia) con respecto a la lengua de los interlocutores en los actos dialogales, en función de los intereses del hablante. Así, en un estudio sobre el grado de adaptación a las normas del Received Pronunciation (RP) entre políticos y periodistas escoceses que trabajan en el Parlamento de Westminster, Brulard y Carr (2013) han advertido que esta acomodación tiene lugar en la práctica y que, además, se realiza de manera inconsciente ante la presencia cotidiana de interlocutores de otras procedencias, preferentemente inglesas. En el corpus de la presente investigación, estos interlocutores son, en muchos casos, periodistas oriundos de regiones españolas ajenas al dominio lingüístico catalán, y por tanto, potencialmente menos receptivos a las reivindicaciones catalanistas. Por tanto, ello podría, o bien atemperar las pulsiones vernáculas de los hablantes, adecuando su habla a las previsibles realizaciones alveolares de aquellos, o, en sentido contrario, acentuar esas articulaciones velarizadas en un intento por subrayar las diferencias. Por el contrario, en los actos prototípicamente monologales, cabría suponer que el hablante se halla menos concernido por esos condicionamientos psicosociales.

- Por último, el estudio tiene en cuenta otros dos factores, que, a diferencia de los anteriores, consideramos como aleatorios en un análisis de regresión logística de efectos mixtos. De este modo, la verdadera incidencia de los predictores se pone a prueba tras su examen en el interior de cada una de las palabras y politicos que las han pronunciado. En consecuencia, ello nos permite comprobar la variabilidad en el seno no solo de los grupos sociales, sino también de los propios idiolectos, y aun de los vocablos donde aparece la variable lingüística. 


\section{Metodología}

Para la realización del estudio se ha recogido un corpus mediante la recopilación de vídeos protagonizados por los políticos mencionados a través de internet. Para facilitar el análisis contrastivo, contamos con una muestra de habla de una hora de duración aproximadamente por cada representante público ${ }^{5}$, repartida en diversos actos comunicativos. Los más frecuentes son las entrevistas, pero no faltan las representaciones de otros géneros, como intervenciones parlamentarias, mítines, ruedas de prensa, declaraciones institucionales, etc.

Todas las muestras de habla se han transcrito mediante la herramienta de escritura de voz del programa Google Doc, cuyas versiones iniciales se han revisado y editado manualmente. A continuación, mediante un programa de concordancias (Wordsmith v. 6.0), se han obtenido todas las ocurrencias de la variable lingüística, y sus realizaciones escritas se han cotejado con las muestras orales que proporcionan los vídeos correspondientes. En aquellos casos en los que, tras la escucha reiterada, la variante no estaba suficientemente clara, los ejemplos se han sometido a un análisis fonético mediante el programa Praat (Boersma y Weenink 2006). Como se indicó más arriba, las dos únicas variantes consideradas son la alveolar y la velar, al margen de que en cada una de ellas quepan realizaciones alofónicas cualitativamente diferentes.

Para el estudio cuantitativo nos servimos inicialmente de una estadística descriptiva, que nos permite obtener una primera radiografía acerca de las tendencias de variación predominantes en forma de frecuencias y porcentajes. Con todo, la verdadera significación de estas medidas tan solo puede emprenderse a través de una estadística multivariante, que en el caso de los estudios variacionistas está íntimamente asociada a los modelos de regresión logística (Baayen 2008; Tagliamonte y Baayen 2012; Levshina 2015). Dentro de estos, en los últimos años han adquirido cada vez más relevancia los modelos de efectos mixtos, aquellos que combinan tanto factores categoriales fijos (sexo, origen social, vocal previa...) como otros de naturaleza continua (año, edad, frecuencia...) y aleatoria (palabra, político). Como señalábamos más arriba, estos últimos son particularmente relevantes para el análisis de la variación, pues permiten corregir eventuales errores en la

\footnotetext{
${ }^{5}$ Con todo, hay que considerar alguna excepción a esta regla. Así, en el caso de Monserrat Candini, probablemente la política menos mediática de todos los incluidos en la muestra, no pudimos pasar de los 40 minutos, ante la imposibilidad de encontrar más material audiovisual. Paradójicamente, ello no ha afectado sustancialmente al número de ocurrencias de la variable, en comparación con el habla de otros miembros de la muestra, mucho mejor representados en el corpus.
} 
interpretación de los resultados ${ }^{6}$, especialmente cuando, como ocurre en este caso, son muchas las ocurrencias de la variable a cargo de cada hablante. De este modo, los modelos de regresión de efectos mixtos permiten validar (o no) la significación de los factores categoriales y continuos tras su cruce con los factores aleatorios, como, en este caso, la palabra y la identidad de los informantes.

Para este análisis, en el presente estudio nos servimos del programa Rbrul (Johnson 2009), cuya interfaz, sencilla e intuitiva, permite acceder a dos de las medidas fundamentales del estudio variacionista:

a) la significación de los factores seleccionados como significativos, y

b) la dirección explicativa en el seno de los correspondientes predictores $^{7}$.

La primera se mide en pesos explicativos (factor weights) o valores $P$., que se sitúan entre los índices extremos de 0 (nulo favorecimiento de una variante) y 1 (selección categórica de la variante). Normalmente, se interpreta que los valores situados por encima de .50 reflejan factores que favorecen una forma determinada, mientras que los localizados por debajo de esa cifra, la desfavorecen. Con todo, algunos autores consideran que lo más relevante es la dirección explicativa de esos índices y no tanto las cifras concretas (Tagliamonte 2012: 173).

Ahora bien, pese a su potencial predictor, los análisis de regresión logística no siempre permiten apreciar fácilmente la relevancia explicativa de estos factores y las sutiles y complejas interacciones que se producen en su interior, especialmente cuando en el estudio se examina un número considerable de estos. Por este motivo, en los últimos años han adquirido carta de naturaleza algunos modelos no paramétricos de regresión que palían estas deficiencias, como los árboles de inferencias condicionales (conditional inferential trees) y los bosques aleatorios (random forest) (Breiman 2001). Con ellos podemos comprobar no solo qué factores (predictores) son más relevantes que otros, sino también el modo en que trabajan en tándem (para más detalles acerca de la interpretación de estos, véase a continuación \$6).

${ }^{6}$ Especialmente, falsos positivos o errores tipo I, como se conocen en el argot variacionista (Tagliamonte 2012: 141). Estos consisten en interpretar como factores explicativos aquellos que no lo son, pese a ser seleccionados como significativos por el programa estadístico. En la práctica, estos factores entran en interacción o son colineales con otros, lo que anula su poder predictivo.

${ }^{7}$ Los resultados de Rbrul serán contrastados en una segunda fase con los obtenidos mediante un análisis de regresión logística de efectos mixtos mediante el paquete party en el entorno R (R Core Development Team 2015). Aunque la interfaz de esta herramienta estadística es mucho menos amable que la de Rbrul, sirve entre otras cosas para confirmar o descartar eventuales diferencias significativas entre algunos factores en el seno de los correspondientes predictores. Como veremos más adelante $(\S 6)$, así ocurre, por ejemplo, en este estudio con algunos de los considerados inicialmente. 


\section{Resultados}

\subsection{Análisis de frecuencias}

La variable cuenta con 1759 ejemplos, de los cuales un $44 \%(n=773)$ corresponde a las variantes velarizadas y un $56 \%(n=986)$ a las realizaciones alveolares. A pesar de que estas últimas, que representan la pronunciación estándar en español, suponen una mayoría, el número de las vernáculas es, sin duda, elevado, más aún si tenemos presente que estamos ante una muestra de población con un nivel sociocultural alto, lo que permitiría aventurar la existencia de cifras potencialmente más elevadas en otros sociolectos de la misma comunidad lingüística.

Ahora bien, la velarización está desigualmente repartida entre los diferentes miembros de la muestra, como revelan los datos de la tabla 3 .

TABLA 3. Distribución de las variantes por informante

\begin{tabular}{|c|c|c|c|c|c|}
\hline \multirow[b]{2}{*}{ Nombre } & \multicolumn{2}{|c|}{ VELAR } & \multicolumn{2}{|c|}{ ALVEOLAR } & \multirow[b]{2}{*}{$\Sigma$} \\
\hline & $\mathrm{N}$ & $\%$ & $\mathrm{~N}$ & $\%$ & \\
\hline Albiol & 39 & 49 & 40 & 51 & 79 \\
\hline Candini & 44 & 60 & 29 & 40 & 73 \\
\hline Chacón & 5 & 4 & 116 & 96 & 121 \\
\hline Colau & 17 & 17 & 81 & 83 & 98 \\
\hline Coscubiela & 30 & 29 & 73 & 71 & 103 \\
\hline Duran & 28 & 28 & 73 & 72 & 101 \\
\hline Forcadell & 67 & 71 & 27 & 29 & 94 \\
\hline Girauta & 31 & 28 & 78 & 72 & 109 \\
\hline Herrera & 1 & 1 & 130 & 99 & 131 \\
\hline Montserrat & 29 & 21 & 106 & 79 & 135 \\
\hline Pascal & 70 & 61 & 44 & 39 & 114 \\
\hline Rivera & 2 & 2 & 79 & 98 & 81 \\
\hline Rovira & 88 & 82 & 19 & 18 & 107 \\
\hline Sànchez & 93 & 60 & 62 & 40 & 155 \\
\hline Tardà & 139 & 89 & 17 & 11 & 156 \\
\hline Turull & 90 & 88 & 12 & 12 & 102 \\
\hline
\end{tabular}


En efecto, y como se puede comprobar de manera más gráfica en la figura 1, hay notables diferencias en las realizaciones velarizadas entre unos políticos y otros. Así, junto a individuos que velarizan prácticamente siempre (el caso de Tardà, Turull y Rovira, con porcentajes superiores al 80\%), otros apenas lo hacen, destacando a este respecto los casos de la exministra socialista, Carme Chacón, el líder de Ciudadanos, Albert Rivera, y el antiguo representante de Iniciativa per Catalunya-Verds, Joan Herrera, del que apenas encontramos una ocurrencia de la variante vernácula entre más de 130. Entre ambos extremos se sitúa el resto de políticos, con contribuciones a la velarización también variables.

GRÁFICO 1. Distribución de la variante velar por informantes (\%)

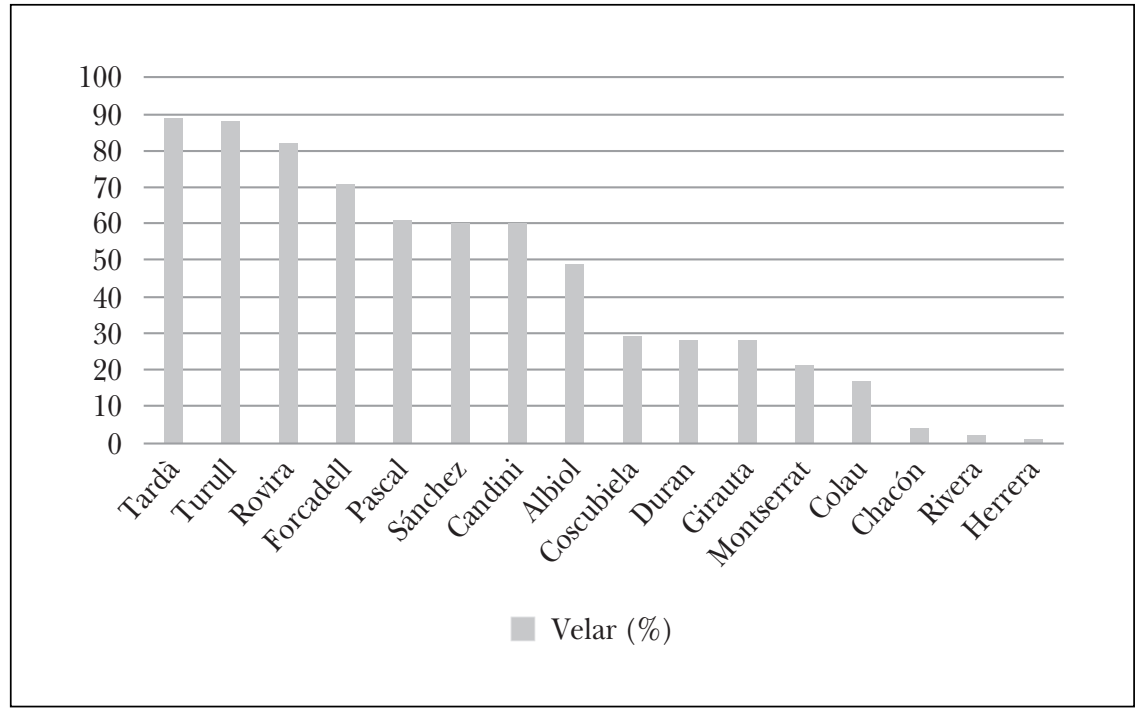

Del mismo modo, la variabilidad aparece desequilibrada en algunos enclaves tanto de la matriz lingüística como social, como informa la tabla 4. En ella se pueden ver las frecuencias absolutas y porcentajes obtenidos por la variante vernácula en cada uno de los factores categoriales considerados, cuando estos se analizan de manera independiente.

De sus datos parece deducirse que, junto a predictores cuyos factores arrojan diferencias mínimas en su interior (sexo, tipo de discurso, clase de palabra, ideología), otros permiten colegir la existencia de divergencias de mayor calado, que, en todo caso, hay que validar mediante un análisis multivariante, en el que los factores se analizan conjuntamente y no por separado. 
TABLA 4. Distribución de la variante velar de -(l) final entre los factores categoriales

\begin{tabular}{|c|c|c|c|c|}
\hline Predictores & FACTORES & $\mathrm{N}$ & $\Sigma$ & $\%$ \\
\hline \multirow{3}{*}{ VOCAL PREVIA } & Palatales & 63 & 314 & 20 \\
\hline & Velares & 119 & 169 & 70 \\
\hline & Central & 591 & 1276 & 46 \\
\hline \multirow{3}{*}{ Contexto siguiente } & Pausa & 391 & 764 & 51 \\
\hline & Vocal & 89 & 267 & 33 \\
\hline & Consonante & 293 & 728 & 40 \\
\hline \multirow{3}{*}{ ClaAse de PALABRa } & Adjetivo & 538 & 1251 & 43 \\
\hline & Otras & 143 & 288 & 49 \\
\hline & Sustantivo & 92 & 220 & 42 \\
\hline \multirow{2}{*}{ NACIÓN } & Nacionalistas & 619 & 902 & 69 \\
\hline & No nacionalistas & 154 & 857 & 18 \\
\hline \multirow{2}{*}{ ORIGEN SOCIAL } & Humilde & 563 & 894 & 63 \\
\hline & Otros & 210 & 865 & 24 \\
\hline \multirow{2}{*}{ IDEOLOGÍA } & Izquierda & 440 & 965 & 45 \\
\hline & Derecha & 333 & 794 & 42 \\
\hline \multirow{2}{*}{ Procedencia } & Barcelona & 218 & 750 & 29 \\
\hline & Resto & 555 & 1009 & 55 \\
\hline \multirow{2}{*}{ SEXo } & Hombre & 453 & 1017 & 44 \\
\hline & Mujer & 320 & 742 & 43 \\
\hline \multirow{2}{*}{ TIPO DE DISCURSO } & Dialogales & 468 & 1009 & 46 \\
\hline & Monologales & 305 & 750 & 41 \\
\hline TOTAL & & 773 & 1759 & 44 \\
\hline
\end{tabular}

\subsection{Análisis de regresión logística de efectos mixtos}

Los resultados de este análisis se muestran en la tabla 5. En ella se puede apreciar cómo tan solo cuatro de los predictores considerados inicialmente son seleccionados como significativos, por su contribución sólida e independiente a la variación de $(-1)$. Por el contrario, ninguno de los otros viene avalado por el programa de regresión. Estos resultados ofrecen, 
además, un buen nivel de fiabilidad, como se desprende del elevado nivel alcanzado por el estadístico Dxy (0.77), que sirve para medir el grado de ajuste del modelo de regresión.

TABLA 5. Contribución de los factores seleccionados como significativos por el modelo de regresión logística de efectos mixtos mediante Rbrul (variables aleatorias: palabra, político)

\begin{tabular}{|c|c|c|c|c|c|}
\hline & \\
\hline & $\mathrm{N}$ & Total $\Sigma$ & $\%$ & Log-odds & FW (P.) \\
\hline \multicolumn{6}{|l|}{ VOCAL PREVIA } \\
\hline Palatal & 63 & 314 & 20 & -1.00 & .27 \\
\hline Central-velar & 710 & 1445 & 49 & 1.00 & .73 \\
\hline Rango & & & & & 46 \\
\hline \multicolumn{6}{|c|}{ Contexto SiguiEnTE } \\
\hline Pausa & 391 & 764 & 51 & 0.36 & .59 \\
\hline Otros & 382 & 995 & 38 & -0.36 & .41 \\
\hline Rango & & & & & 18 \\
\hline \multicolumn{6}{|l|}{ NACIÓN } \\
\hline Nacionalistas & 619 & 902 & 69 & 1.308 & .78 \\
\hline No & 154 & 857 & 18 & -1.308 & .21 \\
\hline Rango & & & & & 57 \\
\hline \multicolumn{6}{|l|}{ ORIGEN SOCIAL } \\
\hline Humilde & 563 & 894 & 63 & 0.878 & .70 \\
\hline Resto & 210 & 865 & 24 & -0.878 & .29 \\
\hline Rango & & & & & 41 \\
\hline
\end{tabular}

n (1759), intercept (-1.161), overall proportion (0.44), log. likelihood (-762.894), AICc (1539.853), Dxy.total (0.77)

En el plano estructural, se confirman las hipótesis iniciales acerca de la incidencia del contexto vocálico previo en las realizaciones de la variable. De este modo, las vocales palatales son, con diferencia, las que menos propician las velarizaciones $(.27 ; 20 \%)$. Estas se oponen al resto de vocales, tanto centrales como velares, cuya contribución conjunta a la realización vernácula de $(-1)$ es mucho más alta $(.73 ; 49 \%)^{8}$.

${ }^{8}$ Para este análisis, hemos agrupado en un solo bloque la vocal /a/ y las vocales velares /o, u/, ya que un análisis de regresión previo, mediante $\mathrm{R}$, demostró que las diferencias entre estas dos clases no eran estadísticamente significativas. 
Lo mismo ocurre con el segundo factor estructural, cuyas cifras arrojan también diferencias significativas. Aunque de menor calado que las anteriores, a la luz de los correspondientes pesos explicativos, concuerdan también con las hipótesis iniciales. Ahora bien, pese a la aparente jerarquía en el seno del Contexto siguiente, entre los entornos prepausales (51\%), consonánticos $(40 \%)$ y vocálicos $(33 \%)$, el análisis de regresión tan solo arroja como significativas las diferencias entre los primeros $(.59 ; 51 \%)$ y la combinación de los segundos, cuya contribución conjunta a las realizaciones velares es moderadamente negativa $(.41 ; 38 \%)$.

En el plano extralingüístico se advierten también dos factores particularmente robustos. Es el caso del origen social de los individuos que, conforme a las hipótesis iniciales, discrimina a la población entre quienes proceden de un entorno social humilde $(.70 ; 63 \%)$ y el resto $(.29 ; 24 \%)$. Como cabía esperar, son los primeros quienes favorecen con más claridad las velarizaciones, frente al comportamiento más cercano al estándar de los segundos.

Con todo, más destacadas parecen aún las diferencias entre los dos grupos formados a partir de su orientación en torno al catalanismo político. De este modo, los políticos que forman el grupo nacionalista consiguen el peso explicativo más elevado de todo el análisis $(.78 ; 69 \%)$, a mucha distancia del correspondiente a los no nacionalistas $(.21 ; 18 \%)$. Por otra parte, un examen contrastivo entre ambos grupos, en el que se compara el comportamiento de nacionalistas y no nacionalistas ante los diferentes contornos estructurales considerados en el estudio, muestra también algunos resultados interesantes. De un lado, comprobamos cómo, pese a las más que notables diferencias frecuenciales entre un grupo y otro, la dirección explicativa es similar en dos de los factores seleccionados. En efecto, la tabla 6 (página siguiente) muestra cómo tanto entre los nacionalistas como entre los no nacionalistas las velarizaciones se ven favorecidas cuando la consonante va precedida por una vocal central o velar, así como cuando sigue una pausa elocutiva. Asimismo, tanto en un grupo como en otro, el primero parece un factor significativamente más determinante que el segundo.

Ahora bien, junto a estas semejanzas, la tabla permite vislumbrar también algunas diferencias. Por ejemplo, el peso del factor Pausa tiene una relevancia mayor en el grupo de políticos nacionalistas (.62) que entre los no nacionalistas (.55). Con todo, más reveladora es la diferente significación del factor longitud de la palabra, medido, como se recordará, a través del número de sílabas. De este modo, comprobamos cómo el logaritmo positivo obtenido entre los nacionalistas (0.186) releva que las velarizaciones, aun abundantes en todo el léxico, se activan todavía más entre las palabras más extensas. De hecho, el análisis de frecuencias muestra la siguiente escala en el número de realizaciones vernáculas dentro de este grupo: palabras con 1 sílaba $(62 \% ; n=114) ; 2$ sílabas $(60 \% ; n=336) ; 3$ sílabas $(76 \% ; n=322)$; 
TABLA 6. Contribución de los factores estructurales seleccionados como significativos para cada una de las submuestras (nacionalistas/no nacionalistas)

\begin{tabular}{|c|c|c|c|c|c|c|}
\hline & \multicolumn{3}{|c|}{ NACIONALISTAS } & \multicolumn{3}{|c|}{ NO NACIONALISTAS } \\
\hline & $\mathrm{N}$ & Total $\Sigma$ & FW (P.) & $\%$ & Total $\Sigma$ & FW (P.) \\
\hline \multicolumn{7}{|l|}{ VOCAL PREVIA } \\
\hline Palatal & 36 & 156 & .27 & 4 & 158 & .26 \\
\hline Central-velar & 75 & 746 & .72 & 21 & 699 & .74 \\
\hline Rango & & & 45 & & & 48 \\
\hline \multicolumn{7}{|c|}{ CONTEXTO SIGUIENTE } \\
\hline Pausa & 79 & 398 & .62 & 21 & 366 & .55 \\
\hline Otros & 60 & 504 & .38 & 16 & 491 & .45 \\
\hline Rango & & & 24 & & & 10 \\
\hline N. ${ }^{\circ}$ SÍLABAS & & & 0.186 & & & -0.211 \\
\hline
\end{tabular}

No nacionalistas: $\mathrm{n}(857)$, intercept $(-2.814)$, overall proportion $(0.18)$, log.likelihood (-330.764), AICc (669.574), Dxy.total (0.67)

Nacionalistas: n (902), intercept $(-0.06)$, overall proportion $(0.69)$, log.likelihood (-433.548), AICc (879.191), Dxy.total (0.66)

4 sílabas $(78 \% ; n=54)$; 5 o más sílabas $(81 \% ; n=76)$. Sin embargo, lo contrario sucede entre los políticos no nacionalistas, siendo ahora las palabras menos extensas las más propensas a ser objeto de velarización, lo que se traduce en un logaritmo negativo (-0.211): palabras con 1 sílaba $(21 \% ; n=62)$; 2 sílabas $(20 \% ; n=381) ; 3$ sílabas $(16 \% ; n=271) ; 4$ sílabas $(12 \% ; n=62)$; 5 o más sílabas $(13 \% ; n=81)$.

\subsection{Modelos de regresión no paramétricos}

Como hemos comprobado, el análisis de regresión logística de efectos mixtos proporciona información muy valiosa acerca de qué predictores contribuyen significativamente a la variación y cuál es la dirección explicativa en su seno, tanto en el conjunto del corpus como en la comparación entre diferentes submuestras. Sin embargo, el modelo estadístico no es tan versátil para revelar las sutiles y complejas interacciones que se observan a menudo en una muestra sociolingüística en la que, generalmente, los datos se hallan distribuidos de manera desequilibrada. Por otro lado, es también dudoso que pueda medir la jerarquía de los predictores, o dicho de 
otra manera, cuáles son más importantes que otros (Tagliamonte y Baayen 2012). Tradicionalmente, en la sociolingüística variacionista esta medida se efectuaba a través de la comparación entre los respectivos rangos (ver tablas 4 y 5), una medida no estadística obtenida mediante la resta entre los pesos explicativos más alto y más bajo respectivamente, y que ha sido cuestionada recientemente (Claes 2014).

Para paliar estos problemas, en la última década han comenzado a proliferar en el campo de la sociolingüística algunos métodos de regresión no paramétricos que ya habían sido ensayados previamente en la investigación psicolingüística (Tagliamonte y Baayen 2012; Levashina 2015; Rosemeyer y Schwenter 2017). De ahí que, en esta fase de la investigación, nos servimos del modelo conocido como árbol de inferencias condicionales (conditional inferential tree). A diferencia de los modelos de regresión logística, que parten de una fórmula matemática para predecir la covariación entre factores y variantes, los árboles de inferencias proceden de una manera distinta, dividiendo los resultados de la variable dependiente de manera binaria y recursiva hasta alcanzar el máximo poder explicativo. Por ejemplo, en el caso que nos ocupa, si la frecuencia de las variantes alveolares y velares difiere significativamente en el cruce con un determinado predictor, el algoritmo continúa con otros, y así sucesivamente hasta alcanzar el mayor grado de significación. De este modo, la recursividad del árbol identifica los predictores que actúan de manera relevante, creando diferentes ramas que aparecen jerárquicamente distribuidas (significación que es medida en valores $p$ ) (Rosemeyer y Schwenter 2017: 20). Como se ha señalado, este método tiene indudables ventajas cuando se trabaja con muestras relativamente pequeñas o con un número de factores elevados (Levshina 2015: 291), así como cuando intervienen factores potencialmente colineales o complejas interacciones (Tagliamonte y Baayen 2012: 171). Con todo, el modelo presenta también algunos inconvenientes, como su destacada sensibilidad a la introducción de pequeños cambios en los datos (Rosemeyer y Schwenter 2017: 20), lo que hace que trabajar con muchos factores a la vez puede dibujar árboles excesivamente intrincados y difíciles de interpretar. De ahí que, en lo que sigue, llevamos a cabo un análisis tan solo con los cuatro factores seleccionados como significativos en el análisis de regresión logística, y cuya distribución aparece en el gráfico $2^{9}$.

Como puede observarse, en el nódulo más elevado del árbol aparece el predictor Nación (Catalanismo), que establece una diferencia inicial entre el modo en que se comportan los políticos nacionalistas y los no nacio-

\footnotetext{
${ }^{9}$ La fiabilidad del modelo es muy elevada, como se desprende del Índice C de concordancia obtenido (.85) (Tagliamonte y Baayen 2012). Estos autores consideran el límite igual o superior a .80 como aquel que da cuenta de los ajustes más fiables.
} 
GRÁFICO 2. Árbol de inferencias condicionadas (conditional inference tree) de la alternancia entre las pronunciaciones velar/alveolar de - $(l)$

$(\mathrm{C}$ index of concordance $=0.85)$

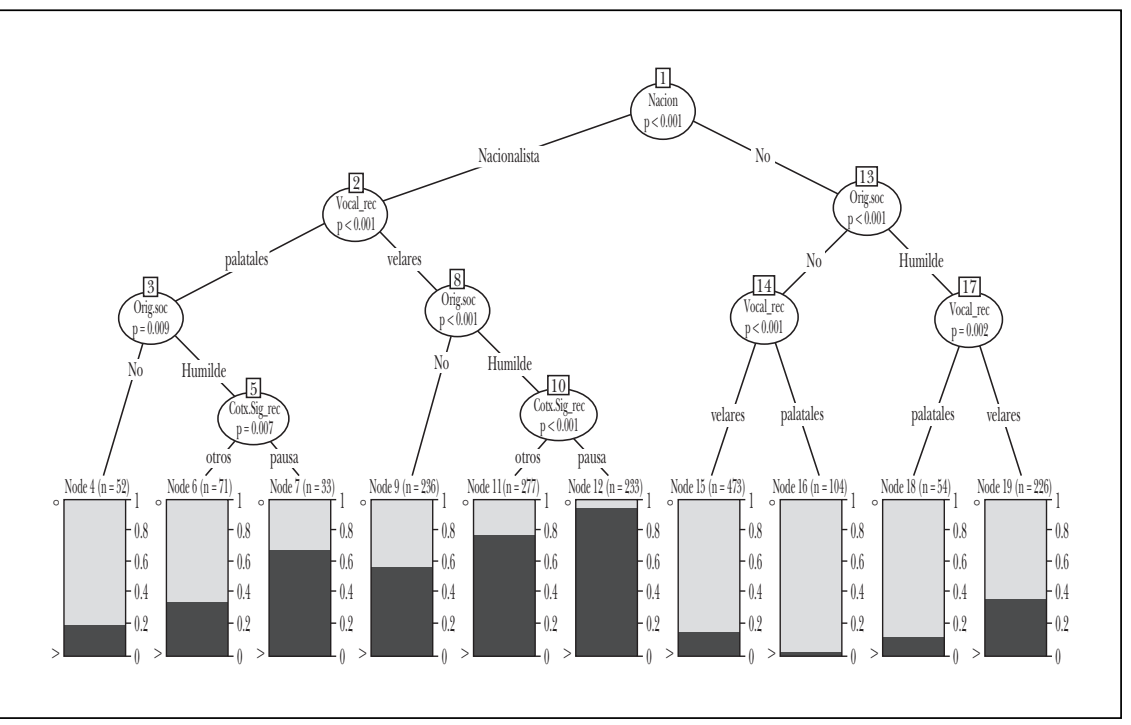

nalistas a través de sendas ramas. La reducida altura de las manchas de color negro en las correspondientes barras inferiores da cuenta de la escasez general de velarizaciones en el grupo no nacionalista, si bien las proporciones de estas difieren en función del origen social de los políticos. De este modo, aquellos que proceden de un origen más humilde velarizan en conjunto más (Nódulo 17), aunque el grado de la variante aparece determinado en última instancia por el contexto vocálico previo: las realizaciones velares son considerablemente mayores ante vocales velares y centrales (Nódulo 19) que ante las palatales (Nódulo 18) ${ }^{10}$. El mismo patrón se aprecia entre los políticos cuyo origen familiar es más acomodado, con la diferencia de que, esta vez, las proporciones adquiridas por la variante vernácula tanto en un contexto vocálico como en otro (Nódulos 15 y 16) se sitúan a considerable distancia de las del grupo anterior.

Lo contrario sucede en el grupo de políticos nacionalistas, situado en la primera rama izquierda del árbol. Estos no solo velarizan mucho más, sino que al mismo tiempo su variación aparece condicionada por un perfil distribucional diferente, al tiempo que más complejo. Así, el nódulo 2 nos informa de la interacción inicial con la vocal previa, estableciendo un

${ }^{10}$ Con el nombre de velares en el árbol se recoge también la central /a/. 
primer contraste significativo entre las vocales centrales y velares, por un lado, y las palatales, por otro. Con todo, aun en este último contexto, el menos proclive a la velarización, el nivel de esta fluctúa en función del origen social de los individuos; e incluso entre los políticos procedentes de una extracción social más humilde -no así en los otros- aparece condicionado por el contexto fónico siguiente, de tal manera que las proporciones de la velarización ante vocal palatal son mayores cuando a la (l) le sigue una pausa (Nódulo 7). Por otro lado, este perfil se repite ante las vocales centrales y velares, con la diferencia ahora de los niveles correspondientes de velarización, siempre mucho más elevados (compárense a este respecto los nódulos 4, 6 y 7 con los 9, 11 y 12, respectivamente).

\section{Conclusiones}

Los datos del estudio demuestran que las velarizaciones de (l) en final de palabra tienen una notable incidencia en la muestra analizada, alcanzando proporciones cercanas a la media (44\%). Teniendo en cuenta que la mayoría de los miembros de esa muestra pertenece a un nivel sociocultural elevado, tanto por formación como por su nivel de ingresos -todos son profesionales vinculados a trabajos institucionales bien pagados, al menos para los estándares españoles-, cabe pensar que las elevadas realizaciones de la pronunciación vernácula responden a motivaciones que van más allá de la tradicional estratificación sociolectal.

Ciertamente, del análisis se desprende que la variación se halla condicionada por algunos factores estructurales, como los contextos previo y siguiente. De este modo, hemos podido comprobar que las velarizaciones son significativamente mayores con las vocales centrales /a/ y velares /o, u/, así como cuando a la (l) le sigue una pausa. Sin embargo, ninguno de los otros factores lingüísticos y estilísticos tomados en consideración muestra significación alguna, ni tras el análisis de regresión logística efectuado, ni tras la realización de un bosque aleatorio (random forest) como el que se muestra en el gráfico 3. Este modelo, que en realidad resume implícitamente la información aportada por un número indefinido de árboles de inferencias condicionadas (conditional inferential trees), con los que está emparentado (Rosemeyer y Swenter 2017: 20), nos permite comprobar la jerarquía de actuación de los predictores considerados en el análisis. Esta se establece a partir del mayor o menor alejamiento del eje vertical: cuanto mayor es ese alejamiento, mayor es al mismo tiempo la relevancia explicativa del predictor, y viceversa.

Efectivamente, en el gráfico puede comprobarse cómo ni la frecuencia, ni la clase morfológica ejercen influencia alguna en la variación de -(1). 
GRÁFICO 3. Jerarquía de los factores en un bosque aleatorio (random forest)

$(\mathrm{C}$ index of concordance $=0.93)$

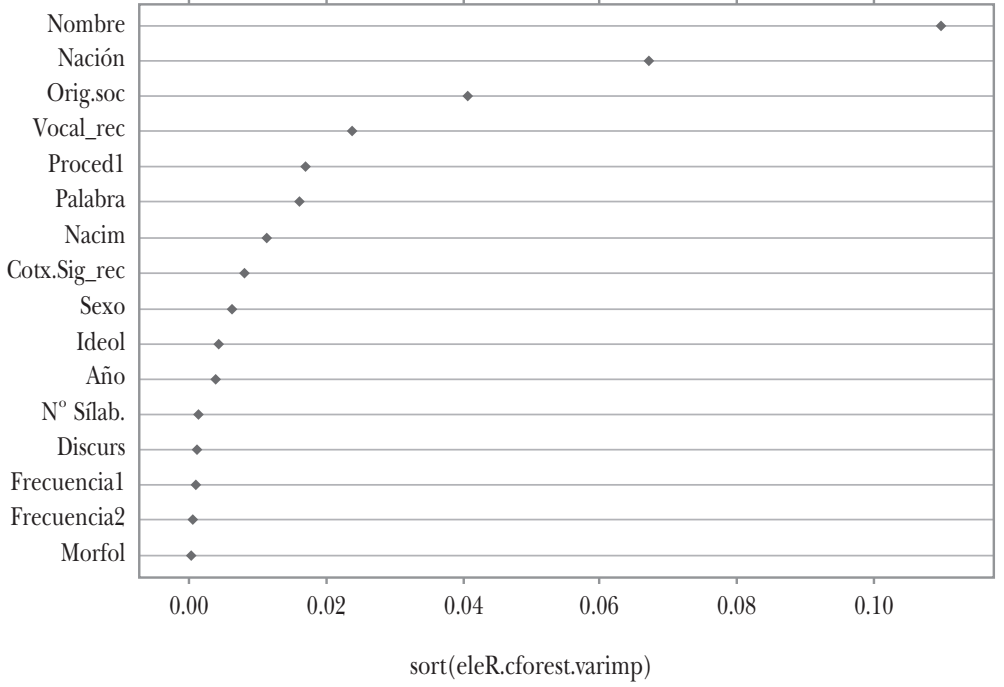

Tampoco lo hace el tipo de discurso, de tal manera que las velarizaciones no se ven afectadas ni por la atención que el político presta a su propia habla en contextos más o menos dialogales o institucionales, ni por las presiones psicosociales que incitan a la convergencia o la divergencia del individuo con respecto al habla de sus interlocutores, hipótesis todas ellas que formulábamos al comienzo de este trabajo y que, sin embargo, no se han visto cumplidas. En este sentido, nuestros resultados difieren de los hallados por Brulard y Carr (2013), a los que nos referíamos anteriormente $(\S 4)$, y se asemejan más a los encontrados más recientemente por Hall-Lew y Friskney (2017), quienes observan que la convergencia hacia las normas del inglés estándar (Received Pronunciation) entre los parlamentarios escoceses en Londres no varía en función del grado de acomodación, sino, al igual que aquí, de acuerdo con parámetros relacionados con la identidad nacionalista de los políticos.

De la misma forma, comprobamos cómo algunos factores extralingüísticos son muy poco explicativos, como sucede con el año del discurso, el sexo o la ideología, agrupados también muy cerca del cero. En relación con este último, y contrariamente, pues, a las premisas iniciales, la velari- 
zación de (-1) no se halla condicionada por la orientación derechista o izquierdista de los políticos. En los últimos años, algunos investigadores han llamado la atención acerca del potencial ideológico de ciertas variables fónicas, cuyas realizaciones alternativas aparecen asociadas al trasfondo más o menos liberal o conservador de los hablantes. Entre la clase política estadounidense, por ejemplo, Hall-Lew, Coppock y Starr (2010) han comprobado cómo la integración de la vocal /a/ en ciertos extranjerismos como Iraq difiere significativamente en función de esa ideología: mientras que las pronunciaciones más respetuosas con la articulación original [a:] se producen entre los congresistas demócratas, lo contrario sucede entre los republicanos, más partidarios de la adaptación a la fonética del inglés [æ]. Con todo, no faltan algunos casos particulares que escapan a esta regla -también en el presente estudio, como veremos-, así como algunos ejemplos de variación intradialectal (Hall-Lew, Stark y Coppock 2012). Sin embargo, en una réplica de este trabajo fuera de la esfera política, Silva et al. (2011), han visto cómo la filiación política conservadora vs. progresista no incide en el grado de nativización de los extranjerismos, siendo este factor superado por otros como la familiaridad y el grado de conocimiento de otras lenguas -en cuyo caso prolifera más [a:]- o el historial militar de los informantes -más [æ].

De regreso a nuestro estudio, es verdad que algunos de los políticos más velarizadores son de izquierdas (Tardà, Rovira, Forcadell), pero otros de esta misma corriente ideológica lo son bastante menos (Coscubiela, Colau) y, aun en ocasiones, prácticamente nunca (Herrera, Chacón). Por no hablar de que en el grupo de los primeros no escasean tampoco los políticos de formaciones derechistas (Turull, Candini, Pascal, Albiol). Sin embargo, el gráfico 3 nos informa de que en cabeza de la jerarquía explicativa se sitúan la identidad de los políticos y su orientación política en torno al nacionalismo, seguidos -ya en una posición menos avanzada- por su origen social.

En relación con el primero hemos visto, en efecto, cómo existe una gran variabilidad entre los dieciséis miembros de la muestra en torno a las realizaciones vernáculas de la variable lingüística. Ahora bien, no es menos cierto que, salvo contadas excepciones, existe un agrupamiento muy sólido en estas realizaciones en función de la adscripción ideológica, nacionalista o no, de los políticos. Ello explicaría que siete de los ocho definidos como nacionalistas figuren en la vanguardia de las velarizaciones, seguidos a una cierta distancia por un político no nacionalista, Xavier Albiol, en cuyos hábitos articulatorios figura también de manera destacada esta realización velar de (-1). Por el contrario, las cifras de los políticos no nacionalistas están muy por debajo, y en algunos casos cercanas a la realización categórica de la variante estándar alveolar, como es el caso de Chacón, Rivera o Herrera, representantes de formaciones ideológicas diferentes. 
Es verdad que esas cifras aumentan en algunos políticos no nacionalistas (Monserrat, Girauta, Coscubiela, Colau), también procedentes de adscripciones políticas diversas, pero en ninguno caso superan estas el umbral del $30 \%$, situándose, pues, claramente por debajo de la media.

Estos resultados vienen a coincidir con los expuestos por Hall-Lew y Friskney (2017) en el artículo al que nos referíamos más arriba. En él, estas autoras describen cómo el cambio hacia las normas estándares del inglés británico se produce significativamente más entre los parlamentarios laboristas que entre los miembros del Partido Nacionalista Escocés, mucho más reacios a abandonar sus realizaciones vernáculas. En el mismo sentido, Krivoruchko (2009) ha llamado la atención sobre el hecho de que, en la Ucrania postsoviética, la elección de las preposiciones $n a$ y $v$ en el sintagma «en Ucrania» parece teñida igualmente por la filiación nacionalista de los hablantes, siendo la primera variante preferida entre los nacionalistas ucranianos y la segunda por los activistas pro rusos. Del mismo modo, en un estudio reciente, nosotros mismos hemos podido advertir esta misma asociación en las realizaciones de otra consonante final, (d), cuyos alófonos sordos [-t], aparecen también elocuentemente más vinculados a los políticos nacionalistas catalanes que al resto (Blas Arroyo 2019).

Ahora bien, junto a estas líneas maestras, en las que se adivina una importante cesura entre ambos grupos de políticos, ¿cómo interpretar el comportamiento divergente de algunos individuos? Por ejemplo, en el grupo nacionalista se incluye un veterano político, cuyo comportamiento velarizador está a mucha distancia $(28 \%)$ de las cifras alcanzadas por sus antiguos compañeros de filas, Josep A. Duran i Lleida. ¿Cómo explicar esa actuación tan diferente? ¿Podría tener algo que ver con su evolución en torno al debate independentista en Cataluña, que para algunos de sus compañeros de filas desembocó en algo parecido a la traición? Hay que recordar que, a diferencia de los otros siete políticos nacionalistas incluidos en la muestra, y aun favorable siempre al derecho a decir, Duran i Lleida abandonó la senda proclive a la independencia que habrían de recorrer muchos de sus antiguos correligionarios. De hecho, en 2017, Duran i Lleida publicó un libro, titulado Un pa com unes hòsties (en la versión española, Un pan como unas tortas), en el que criticaba con dureza la deriva independentista de tantos socios de su antigua formación. Ello, unido al fracaso electoral en las elecciones al parlamento catalán de 2015 encabezando ya en solitario su partido -Unió Democràtica- y a algunas condenas por corrupción de este último, llevó a Duran a abandonar definitivamente la política activa. Al mismo tiempo, puede ser también revelador el hecho de que Duran i Lleida sea uno de los pocos ejemplos de la muestra en los que se aprecia una evolución descendente de las velarizaciones con el paso del tiempo, como muestra el gráfico 4 . 
GRÁFICO 4. Evolución de las velarizaciones en el discurso de Duran i Lleida durante el periodo analizado (\%)

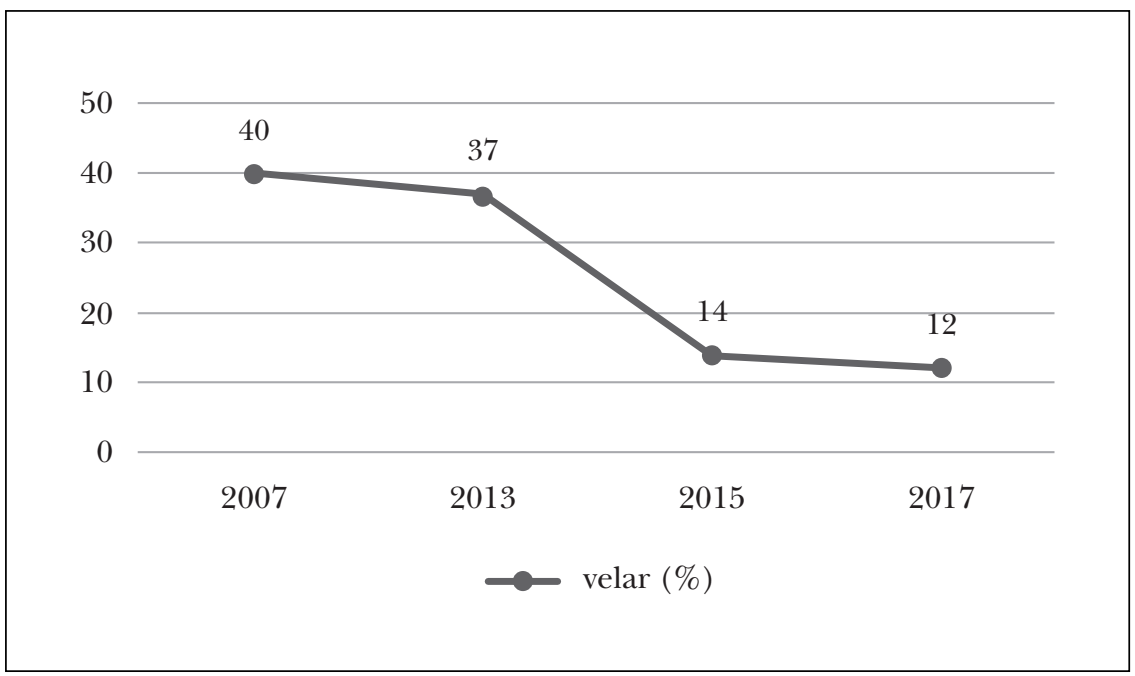

Como revela esta secuencia, con el transcurrir de los años, y en paralelo al descabalgamiento de la senda independentista, el político nacionalista parece haber ido atenuando las realizaciones vernáculas de (l) que en otro tiempo formaron parte de sus señas de identidad lingüística, y que no tenía empacho en utilizar recurrentemente en sus intervenciones tanto en el parlamento español en el año 2007 como en el programa de TVE Tengo una pregunta para usted del año 2013, cuando, todavía asentado firmemente en el ideario nacionalista, se enfrentaba a las preguntas incómodas de varios ciudadanos.

En definitiva, lo que revelan estos resultados es que el eje nacionalismo/ no nacionalismo podría reinterpretarse más cabalmente como independentismo/no independentismo, estando las realizaciones velares de $(-1)$ particularmente asociadas al primer polo.

Otro ejemplo singularmente divergente es el representado por Xavier Albiol. En el momento de escribir estas líneas, Albiol lideraba desde hacía unos años el Partido Popular en Cataluña, tras su éxito - no exento de polémica por una política que algunos tildaron de racista y antiinmigratoriaal frente de Badalona, la tercera ciudad más poblada de Cataluña, y donde tradicionalmente habían triunfado siempre los partidos de izquierdas. Albiol representaba, pues, para el Partido Popular -en las antípodas del nacionalismo catalán- una baza convenientemente autóctona, alejada, pues, de las bases tradicionalmente mucho más acomodadas y "españolis- 
tas" del partido conservador. De origen humilde, a Albiol se le 'notaba' inmediatamente su carácter vernáculo al hablar. No solo hablaba en catalán asiduamente, sino que cuando lo hacía en castellano teñía su habla de realizaciones autóctonas: velarizaba con frecuencia la (1) -también en otras posiciones no contempladas en el estudio-, eludía en la pronunciación de la (d) final de palabra las articulaciones más castizas de otras variedades peninsulares [berdá, berdá] (Blas Arroyo 2019), por no hablar de la presencia habitual en su discurso de calcos del catalán («... cualquier mínimo movimiento no tan solo por parte de los responsables de los Mossos d'Esquadra»; «... a labrarse un futuro a tirar hacia delante») y fenómenos de convergencia como la pluralización de haber existencial («... habian, pues, 700, 800 personas...»).

En el marco de lo que se ha dado en llamar tercera ola de estudios variacionistas, Eckert $(2008,2012)$ ha llamado la atención acerca del potencial agentivo de las variables lingüísticas, cuyas realizaciones ya no son el mero reflejo de constructos sociales predefinidos, como el sexo o la clase social, sino también el marco en el que los hablantes pueden crear y recrear sus respectivas identidades, sean estas individuales o colectivas. Además, la investigadora norteamericana ha concluido que las variables no son transmisoras de significados sociales monolíticos, sino que, por el contrario, estos se actualizan en diferentes grupos o comunidades de actividad en función de los intereses de los hablantes, ya sea de manera consciente o inconsciente (en este último caso a través de la repetición o habitus) (en el mismo sentido, véase también Podesva et al. 2015). Estos ámbitos indiciarios (indexical fields), cuyos significados específicos se concretan en contextos determinados, podrían explicar los diferentes significados sociales que la velarización de (1) tiene para unos y otros representantes de la clase política catalana. Para la mayoría de los nacionalistas, la realización vernácula es una fértil manifestación de una ideología política que tiñe la otra lengua de la comunidad -la considerada como invasora o, cuando menos, no propia- de las suficientes dosis de catalanidad como para hacerla familiar y reconocible. Con todo, no todos los nacionalistas participan de este significado con la misma intensidad. En cabeza se sitúan los líderes del procés, aquellos que viven las aspiraciones independentistas con particular intensidad, con independencia de su ideología más o menos conservadora o progresista. Por el contrario, otros políticos (no menos) nacionalistas parecen atemperar sus realizaciones vernáculas en paralelo a su desengaño con el proceso soberanista, como parece ser el caso de Duran i Lleida.

¿Y qué ocurre con Albiol? Para este político, la identificación con las velarizaciones -bien es verdad que todavía a distancia de los políticos nacionalistas más destacados- parte del mismo carácter vernáculo de estas, de su identificación con lo autóctono y lo familiar, pero esta vez con una 
lectura radicalmente distinta a la del ideario nacionalista: la interferencia en el español de Cataluña no es la manera de neutralizar esta lengua, sino un emblema de la fusión entre dos identidades, la catalana y la española, que están en la base de la ideología no nacionalista (o, como algunos quieren, españolista). Claro que esta no es tampoco la única forma de manipular la realidad lingüística en estos sectores, ni siquiera la principal. Y es que, como hemos tenido ocasión de comprobar, para otros políticos no nacionalistas, cuanto más alejados estén los hábitos articulatorios de ambas lenguas, mejor.

Queda para el futuro la tarea de indagar acerca de si estos significados sociales se extienden también a otros fenómenos de variación fónica o, incluso, gramatical y discursiva. 


\section{BIBLIOGRAFÍA}

BAAYEN, Harald (2008): Analyzing linguistic data. A practical introduction to statistics using $R$, Cambridge: Cambridge University Press.

BADIA, Antoni M. (1981): «Peculiaridades del uso del castellano en las tierras de lengua catalana». En Ricardo Velilla (ed.), Actas del I Simposio para profesores de Lengua y Literatura Españolas, Madrid: Castalia, 11-31.

- (1983): Gramática catalana, Madrid: Gredos.

Blas Arroyo, José Luis (2004): «El español actual en las comunidades del ámbito lingüístico catalán». En Rafael Cano Aguilar (coord.), Historia de la Lengua Española, Barcelona: Ariel, 1065-1086.

— «Spanish in Contact with Catalan». En Manuel Díaz Campos (ed.), Handbook of Hispanic Sociolinguistics, Oxford: Blackwell, 374-394.

- (2019): «Covert and overt prestige in the nationalistic discourse: Variation and identity in the Catalonian procés», Spanish in Context 16,3 (en prensa).

Boersma, Paul y David Weenink (2006): Praat: Doing phonetics by computer, <http:// www.fon.hum.uva.nl/praat/>.

Breiman, Leo (2001): «Random forests», Machine Learning 45, 5-32.

BRULARD, Inès y Philip CARR (2013): «Variability, unconscious accent adaptation and sense of identity: The case of RP influences on speakers of Standard Scottish English», Language Sciences 39, 151-155.

BybeE, Joan L. (2006): «From usage to grammar: The mind's response to repetition», Language 82, 711-733.

CARreras, Jordi, Josep Comas y Josep Pi (1992): Fonética catalana, Barcelona: Teide.

ClaEs, Jeroen (2014): The pluralization of presentational haber in Caribbean Spanish. A study in cognitive construction grammar and comparative sociolinguistics, Tesis Doctoral, Antwerpen: Universiteit Antwerpen.

ECKERT, Penelope (2008): «Variation and the indexical field», Journal of Sociolinguistics 12, 453-476.

- (2012): «Three waves of variation study: The emergence of meaning in the study of sociolinguistic variation", Annual Review of Anthropology 41, 87-100.

Institut D'Estudis Catalans (IEC) (2016): Gramàtica de la llengua catalana, Barcelona: Institut d'Estudis Catalans.

Fernández Planas, Ana M. ${ }^{\mathrm{a}}$ (2011): Asi se habla. Nociones fundamentales de fonética general y española. Apuntes de catalán, gallego y euskara, Barcelona: Horsori.

Giles, Howard, Nicholas Coupland y Justine Coupland (1991): «Accommodation theory: Communication, context and consequence». En Howard Giles et al. (eds.), Contexts of accommodation: developments in applied sociolinguistics, Cambridge, UK: Cambridge University Press, 1-68.

HALl-Lew, Lauren, Elizabeth COPPOCK y Rebecca STARR (2010): «Indexing political persuasion: Variation in the Iraq vowels», American Speech 85/1, 91-102. 
—, Rebecca STARR y Elizabeth CoPPOCK (2012): «Style-shifting in the U.S. Congress: The vowels of Iraq(i)». En Juan A. Hernández Campoy y Juan A. Cutillas Espinosa (eds.), Style-shifting in public: New perspectives on stylistic variation. Ámsterdam: John Benjamins, 45-63.

— y Ruth FRISKNEY (2017): «Accommodation or political identity: Scottish members of the UK Parliament», Language Variation and Change 29, 341-363.

HidAlgo, Antonio y Mercedes Quilis (2012): La voz del lenguaje: fonética y fonología del español, Valencia: Tirant Humanidades.

HuAlde, José I. (2014): Los sonidos del español, Cambrigde UK: Cambrigde University Press.

Johnson, Daniel E. (2009): «Getting off the GoldVarb standard: Introducing Rbrul for mixed-effects variable rule analysis», Language and Linguistics Compass 3/1, 359-383.

KrivoruchKo, Julia G. (2008): «Prepositional Wars: When Ideology Defines Preposition». En Dennis Kurzon y Silvia Adler (eds.), Adpositions: Pragmatic, Semantic and Syntactic Perspectives, Ámsterdam: John Benjamins, 191-208.

Labov, William (1972): Sociolinguistic patterns, Philadelphia: University of Pennsylvania Press.

- (2001): Principles of Linguistic Change: Social Factors, Oxford: Blackwell.

Le Page, Robert y Katherin Tabouret-Keller (1985): Acts of Identity, Cambridge UK: Cambridge University Press.

Levshina, Natalia (2015): How to do linguistics with $R$, Ámsterdam: John Benjamins.

Martínez Celdrán, Eugenio y Ana M. ${ }^{a}$ Fernández Planas (2013): Manual de fonética española: articulaciones y sonidos del español, Barcelona: Ariel.

Podesva, Robert J., Jermay Reynolds, Patrick Callier y Jessica Baptiste (2015): «Constraints on the social meaning of released /t/: A production and perception study of U.S. politicians», Language Variation and Change 27, 59-87.

PRIETO, Pilar (2011): Llengua catalana: fonètica: fonologia i morfología, Barcelona: UOC.

QueEn, Robin (2013): "Gender, sex, sexuality, and sexual identities». En Jack Chambers y Natalie Schilling (eds.), The Handbook of Language Variation and Change, Malden, MA: Wiley-Blackwell, 368-386.

Quilis, Antonio, Manuel Esgueva, M. ${ }^{a}$ Luz Gutiérrez Araus y Margarita CantareRO (1979): «Características acústicas de las consonantes laterales españolas», Lingüistica Española Actual 1, 233-343.

R Development Core Team (2015): $R$ : A language and environment for statistical computing, Vienna, Austria: The R Foundation for Statistical Computing. <http://www.R-project.org>.

Rosemeyer, Malte y Scott A. Schwenter (2017): «Entrenchment and persistence in language change: The Spanish past subjunctive», Corpus Linguistics and Linguistic Theory, publicado online el 14/02/2017. (DOI: https://doi.org/ 10.1515/cllt-2016-0047).

Silva, David J., Sharon A. Peters, Fahad Ben Duhaish, Sok-Hun Kim, Yilmin Koo, Lana MARJI y Junsuk PARK (2011): "Variation in the Iraq vowels outside the public forum: The indexing of political persuasion reconsidered», American Speech 86/2, 179-191. 
SinNer, Carsten (2004): El castellano de Cataluña, Tubinga: Max Niemeyer Verlag. SinNer, Carsten y Andreas Wesch (eds.) (2008): El castellano en las tierras de habla catalana, Frankfurt/Madrid: Vervuert/Iberoamericana.

Tagliamonte, Sali A. (2012): Variationist sociolinguistics: Change, observation, interpretation, Malden, MA: Wiley-Blackwell.

- y Harald BAAYEN (2012): «Models, forests and trees of York English: Was/ were variation as a case study for statistical practice», Language Variation and Change 24/2, 135-178.

TrudgiLl, Peter J. (2000): Sociolinguistics: An Introduction to Language in Society, London: Penguin. 